(C) 2019 by the Massachusetts Institute of Technology. This is the accepted manuscript of an article published by MIT Press in Linguistic Inquiry, available online: https://doi.org/10.1162/ling_a_00370

\title{
On adjoined possessors
}

\section{András Bárány}

Leiden University
Irina Nikolaeva

SOAS University of London

1 External, internal and intermediate possessors

Possessors that do not form a constituent with the possessed noun they are in a possessive relation with ("external possessors") are found in many languages and have been widely discussed in the literature (see e.g. Lee-Schoenfeld 2016 on German, Landau 1999 on Hebrew, and Deal 2013 on Nez Perce). When external possessors have a different case from possessors that are internal to the noun phrase, this case is assigned by a head in the functional structure of the clause which in some instances also assigns a semantic role such as BeNEFACTIVE or MALEFACTIVE to the possessor, marking it as an affected participant. Not surprisingly, external possessors can participate in clause-level syntactic processes. For instance, they can control agreement with the predicate (e.g. Deal 2013) or participate in switch-reference (SR; see e.g. Broadwell 2006, Munro 2016 on external possessors and SR in the Muskogean languages Choctaw and Chickasaw). Internal possessors, in contrast, do not generally show such "external" behavior. The distinct behavior of external and internal possessors follows from their distinct syntax.

(1) a. External possessor

$\ldots \mathrm{T}\left[_{\nu \mathrm{P}} \mathrm{DP}_{\mathrm{SBJ}}\left[v\left[_{\text {SpecFP }}\right.\right.\right.$ Possessor [ F [VP $\left.\left.\left.\left.\left.\mathrm{V} \mathrm{DP}_{\text {ов }}\right]\right]\right]\right]\right]$ 
b. Internal possessor

$\ldots v\left[{ }_{\mathrm{VP}} \mathrm{V}{\left[\mathrm{DP}_{\text {ов }} \mathrm{D}[\mathrm{PossP}\right.}\right.$ Possessor [ Poss [ $\left.\left.\left.\left.\left.\mathrm{NP}^{\mathrm{N}}\right]\right]\right]\right]\right]$

In (1a), the possessor is in the specifier of "FP", the projection of a functional head F that assigns case to it. FP, which can represent different phrases across languages, is in the extended projection of the verb and its specifier position is thus accessible in the clause, for example for agreement with $v$. This can give rise to object agreement with a possessor rather than the object DP (as e.g. in Nez Perce). Similarly, in Choctaw and Chickasaw, possessors can be promoted to subject and thus participate in SR regularly, just like non-derived subjects.

In contrast, (1b) shows a DP-internal possessor, embedded below a D head. In this position, the possessor is not accessible for DP-external agreement or semantic role assignment and forms a constituent with the possessed noun. This is the standard analysis of internal possessors, applicable to many languages (cf. Szabolcsi 1994, Alexiadou et al. 2007:570-575).

In this paper, we discuss possessors that are in some sense "intermediate" with respect to the internal vs. external distinction: they form a syntactic constituent with the possessed noun but nevertheless show some clause-level behavior, as if they were in a DP-external position. Possessors that have both internal and external properties are discussed, for instance, by Lødrup (2009) for Norwegian, but he does not relate this phenomenon to the structure of the noun phrase. In contrast, the present paper argues, building on May (1985), Chomsky (1986), Kayne (1994), that other languages with such "intermediate" possessors provide syntactic evidence for a representation like (2), in which the possessor is adjoined to the possessive noun phrase, rather than fully contained in it.

(2) $[\mathrm{XP}$ Possessor $[\mathrm{XP} \operatorname{SpecXP}[\ldots \mathrm{NP}]]]$ 
Although adjoined possessors are not widely accepted, similar structures involving adjunction have been proposed for Serbo-Croatian (Despić 2013), Hungarian (É. Kiss 2002, Dékány 2015), and Turkish (Bošković and Şener 2014).

While we will briefly comment on these languages, our focus is on Tundra Nenets (TN; Samoyedic, Uralic; Nikolaeva 2014). The main contribution of the paper lies in providing a detailed and unified analysis of the DP structure and the behaviour of adjoined possessors in TN in a Minimalist framework (in contrast to previous literature, in particular Nikolaeva and Bárány 2019). We will propose that "XP" in (2) is in fact a DP in TN, in contrast to NP in Serbo-Croatian, as argued by Despić (2013), and Turkish, as argued by Bošković and Şener (2014), but perhaps similarly to Hungarian. TN possessors in the adjoined position show hybrid behavior: on the one hand, they are not promoted to an argument function and not interpreted as affected or assigned DPexternal case, but on the other, they behave like arguments with respect to syntactic locality, for example being able to bind into other DPs and participate in SR.

We discuss the position and DP-internal properties of possessors in TN in Section 2, and their DP-external syntax in Section 3, while in Section 4 we situate our analysis of $\mathrm{TN}$ in the existing literature on the structure of the DP and discuss how it addresses conceptual challenges to adjoined possessors that have been raised in the past.

\section{Lexical possessors in Tundra Nenets}

TN has two types of DP-internal lexical possessors. Both are in the genitive, but only one type triggers agreement on the possessum, see $(3 a, b)$, with the same meaning. The distribution of demonstrative pronouns in the DP shows that the agreeing possessor is in a higher position, preceding the demonstrative. ${ }^{1}$

(3) a. t'uku Wera-h ti /*te-da

this Wera-GEN reindeer reindeer-3sG.POss 
b. Wera-h $\boldsymbol{t}^{\prime} \boldsymbol{u} \boldsymbol{k} \boldsymbol{u}^{\circ}$ te-da $\quad$ * $t i$

Wera-GEN this reindeer-3sG.POSS reindeer

'Wera's reindeer'

(Nikolaeva and Bárány 2019:254)

We call agreeing lexical possessors prominent internal possessors (PIPs). We only focus on lexical possessors in this paper; while pronominal possessors in $\mathrm{TN}$ also control possessive agreement, they show distinct syntactic properties in other respects.

Evidence that both PIPs and regular possessors are internal to the DP comes from their identical behavior in standard constituency tests. This is demonstrated for PIPs in (4)-(6). Example (4) shows that the PIP cannot be separated from the possessed noun by sentence adverbs, even though their position is otherwise quite free. Other types of adverbs behave in the same way. In (5), a possessive phrase with a PIP is coordinated with another DP, using tad'ekaxzt ${ }^{\circ}$. This element can coordinate possessors inside a DP as well, and there is no evidence for verb ellipsis in (5), indicating that it involves real DP coordination. For coordinated subjects, as in (5), Nikolaeva (2014:416-417) provides further examples with coordinated possessors and shows that the verb agrees with the DP whose person is higher on the hierarchy $1>2>3$ and in number with the coordinated phrase (Nikolaeva 2014:416). Finally, (6) demonstrates that possessive phrases with PIPs can be contrastively focused as one constituent. ${ }^{2}$
(4)
$\begin{array}{lll}\text { (yetr } \boldsymbol{i}) \text { Wera- } h \quad\left(\text { *yetr }^{\prime} \boldsymbol{i}\right) & \text { te- } x^{\circ} n \partial q-t a & t 0^{\circ}-d \partial m-c^{\circ} \\ \text { always Wera-GEN always reindeer-LOC.PL-3sG.POSs come-1sG-PST }\end{array}$

'I (always) arrived on Wera's reindeer.'

(Nikolaeva 2014:144)

(5) [ Pet'a-h n'a-da tad'ekaxat ${ }^{\circ}$ pidor $\left.^{\circ}\right]$ to ${ }^{\circ}-d^{\prime} i h$

Petya-GEN friend-3sg.POSs and 2SG come-2DU

'Petya's friend and you came (together).' (Nikolaeva and Bárány 2019:231) 
(6)

Petya-GEN friend-ACC-3sg.Poss meet-1sg Masha-ACC NEG-1sG.SBJ>SG.OBJ

'I met [ Petya’s friend ] $]_{\mathrm{Foc}}$, not Masha.' (Nikolaeva and Bárány 2019:231)

These data indicate that PIPs form a constituent with the possessed noun. Since the coordinate structure constraint holds in TN (Nikolaeva 2014:314), (5) also shows that PIPs are not extracted covertly, as in Deal's (2013) analysis of covert possessor raising in Nez Perce, but are in fact DP-internal.

To the degree that external possession is possible at all in $\mathrm{TN}$, it is only found when the host of the possessor is an (intransitive) subject and it involves topicalisation of the possessor (Nikolaeva 2014:222). This is a different construction not addressed here. In the data discussed in the rest of this paper, where a PIP is hosted by a subject, it is never a topicalized, external possessor, but an internal possessor, as was confirmed by the application of the tests cited above.

Possessors can be stacked, but stacking is not possible with more than one PIP, as in

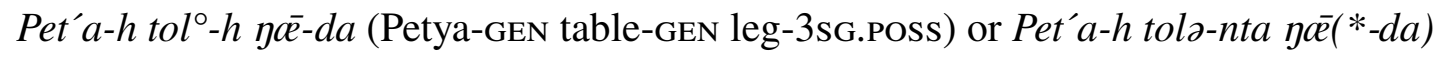
(Petya-GEn table-GEn.3sg.Poss leg(*-3sg.Poss)) 'the leg of Petya's table'. This example also shows that PIPs can be non-human, although such constructions are not particularly frequent. While the examples below illustrate human PIPs, this is not a categorical condition, and there are generally no clear semantic restrictions on PIPs.

\section{Evidence for PIPs c-commanding out of DP}

The syntax of PIPs differs from that of regular possessors. Their high DP-internal position allows them to show certain clause-level properties and PIPs, in contrast to regular possessors, can c-command out of the DP that hosts them.

The first piece of evidence comes from binding. (7) shows that regular possessors of the subject cannot bind possessors of the object represented either by a possessive suffix (possibly with an associated pro possessor) only, (7a), or a possessive suffix and 
an overt pronoun, (7b). Possessors referenced by a possessive suffix (and possibly pro) can be bound by the subject, (7a), overt pronominals must be free, (7b). ${ }^{3}$

(7) a. [ Wera-h n'e $\boldsymbol{e}^{\circ} \boldsymbol{k a}$ ] [ов pro wen'ako-m-ta] jəwla Wera-GEN brother dog-ACC-3sG.POSS feed.3sG

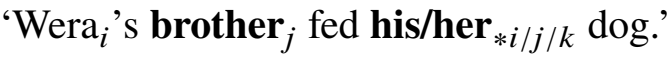

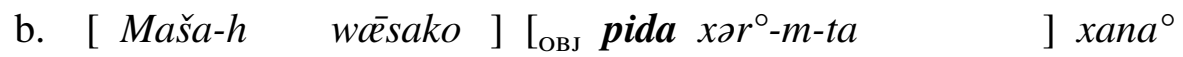

Masha-GEN husband he knife-ACC-3sg.Poss take.3sG

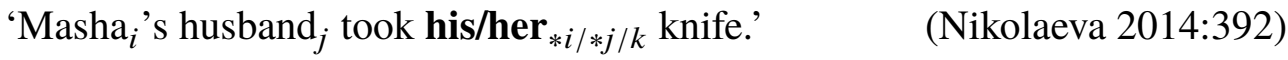

PIPs, in contrast, can bind both null and overt possessive pronouns, as shown in (8a,b).

(8) a. [ Wera-h $n^{\prime} e^{\circ} k a-d a$ ] [ов pro wen'ako-m-ta ] pəwla

Wera-GEN brother-3sg.POss dog-ACC-3sG.POss feed.3sG

'Wera ${ }_{i}$ 's brother fed his $_{i / j / k}$ dog.'

b. [ Wera-h n'abako-da ] [овц pida m'a-kºnanata ] yil' $e^{\circ}$

Wera-GEN sister-3sg.Poss 3sg tent-LOC.3sg.Poss live.3sg

'Wera ${ }_{i}$ 's sister $_{j}$ lives in his/her ${ }_{i / * j / k}$ tent.' $\quad$ (Nikolaeva 2014:392)

The difference between (7) and (8) follows if PIPs but not low possessors are able to c-command out of the DP and thus bind a possessive pronominal in a lower argument.

Additional evidence comes from SR. The same-subject converb in $-\left(s^{\prime} / c^{\prime}\right)^{\circ}$ requires its null subject to corefer with the subject of the superordinate clause. This null subject is arguably PRO: it can be bound by the c-commanding superordinate subject but no other superordinate argument and it cannot have free reference either, as shown in (9). These properties are characteristic of obligatory control (OC) (Landau 2013:29). 
(9) $\left[\right.$ tol $^{\circ}-h \quad t^{\prime} a x^{\circ} n a$ yamt $\left.^{\prime}-^{\circ}\right]$ Wera Pet'a-m monequa

table-GEN at sit-ss.cvi Wera Petya-ACC see.3sg

'Wera ${ }_{i}$ saw Petya ${ }_{j}$ while $\varnothing_{i / * j / * k}$ sitting at the table.'

(Nikolaeva and Bárány 2019:238)

Structure (2) for DP-internal possessors in TN predicts that PIPs should also be able to control the subjects of converbial clauses, while lower possessors should not. This is true. In (10), where the subject hosts a low lexical possessor, only the possessed subject itself, but neither its possessor nor the object can corefer with embedded subject. The order of the converbial clause and the matrix clause does not affect the possibility of control, as Nikolaeva (2014:383-384) also shows for another ss-converb.

(10) a. [ tol ${ }^{\circ}-h \quad t^{\prime} a x^{\circ} n a$ yamt $^{\prime} o^{\circ}{ }^{\circ}$ ] Wera-h n'îs'a Pet'a-m monequa table-Gen at sit-ss.cvB Wera-gen father Petya-ACC see.3sg 'Wera ${ }_{i}$ 's father ${ }_{j}$ saw Petya ${ }_{k}$ while $\emptyset_{* i / j / * k}$ sitting at the table.'

(Nikolaeva 2014:378)

b. Wera-h n'iss'a Pet'a-m moneqya [ tol $^{\circ}-h \quad t^{\prime} a x^{\circ} n a$ yamt $^{\prime} \mathrm{o}^{\circ}$ ]

Wera-GEN father Petya-ACC see.3sg table-GEN at sit-ss.CVB 'Wera ${ }_{i}$ 's father ${ }_{j}$ saw Petya $_{k}$ while $\varnothing_{* i / j / * k}$ at the table.'

(Second author's field notes)

PIPs, however, can control the subject of a converbial clause. In (11), the agreeing possessor precedes the demonstrative, showing that it must be a PIP, and the null subject of the converbial clause can corefer with the main clause subject's possessor. 


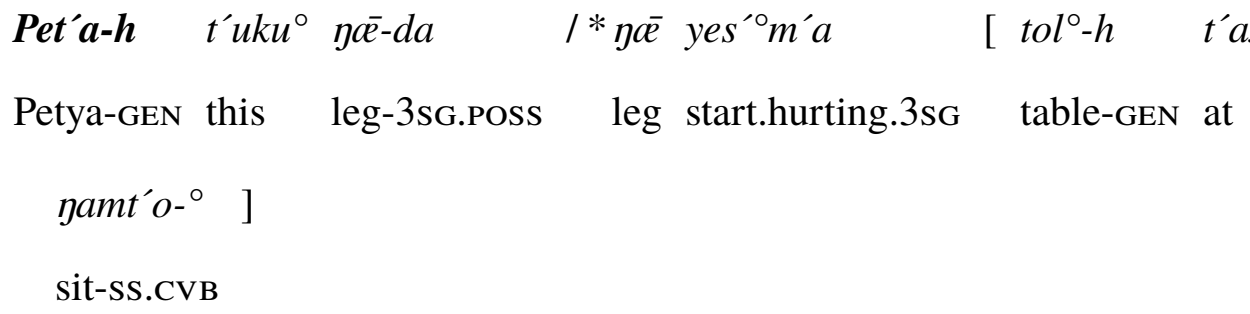

'This leg of Petya ${ }_{i}$ 's started hurting when he ${ }_{i}$ was sitting at the table.'

(Nikolaeva and Bárány 2019:255)

An anonymous reviewer noted that (11) might involve non-obligatory control (NOC), suggesting that $\eta \bar{e}-d a$ 'leg (3sG.POSs)' cannot be a controller due to the odd semantics resulting if it were. But the control relation between the possessor and the embedded subject in (11) is only possible because the possessor is not a regular possessor, but a PIP: replacing $\eta \overline{\bar{Q}}-d a$ with $\eta \overline{e^{2}}$ does not allow the same interpretation.

(12) provides further evidence that PRO in the converbial clause is OC PRO. Landau (2013:ch.7) argues that PRO in NOC must have a [+human] controller. If, therefore, a [-human] referent can control PRO, the relation cannot be NOC. In (12a), with a low lexical possessor, the embedded subject is controlled by the possessed noun kniga 'book', giving rise to an odd interpretation rather than an interpretation with the possessor as the controller. The same logic holds for (11): in the absence of a PIP, SR constructions are not rescued if the controller yields an unusual interpretation. This establishes that the relation is not NOC. In (12b), with a PIP, the possessor of the main clause subject controls the embedded subject. This contrast indicates that the relation involved here is not logophoric control (Williams 1992, Sichel 2010), since the inanimate controller kniga 'book' cannot be a logophor. Rather, the contrast involves a categorical morphosyntactic difference.

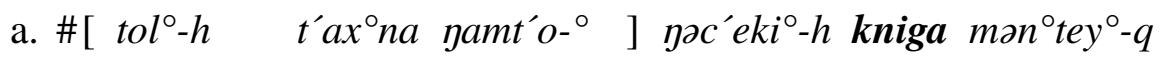

$$
\begin{aligned}
& \text { table-GEN at sit-sS.CVB child-GEN book fall-REFL.3sg }
\end{aligned}
$$

'Sitting at the table, the child's book fell.' 


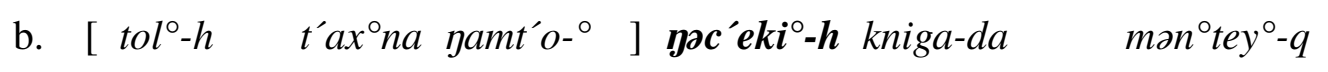
table-GEN at sit-ss.cVB child-GeN book-3sg.POss fall-REFL.3sg 'When it ${ }_{i}$ was sitting at the table, the child ${ }_{i}$ 's book fell.'

(Nikolaeva 2014:380)

That PIPs are able to c-command out of the possessive DP arguably explains restrictions on their distribution. PIPs cannot co-occur with certain other third person DPs in the same minimal clause (Nikolaeva and Bárány 2019). First, PIPs cannot appear if the subject of the clause is third person, unless the subject itself hosts the PIP. PIPs are compatible with first and second person subjects, however. This is shown in (13).

a. Maša [ Wera-h ti-m

/*te-m-ta

] $l a d \partial^{\circ}$

Masha Wera-GEN reindeer-ACC

reindeer-ACC-3sG.POSs hit.3sG

'Masha hit Wera's reindeer.'

b. $\operatorname{mon}^{\circ}[$ Wera-h ti-m

/ te-m-ta

] $l a d \partial^{\circ}-d^{\circ} m$

I

Wera-GEN reindeer-ACC

reindeer-ACC-3sG.POSS hit-1sG

'I hit Wera's reindeer.'

(Nikolaeva and Bárány 2019:243)

Second, PIPs cannot occur when the third person object controls agreement on the verb, unless the object hosts the PIP.

a. [ Wera-h $\left.n^{\prime} e^{\circ} k a\left(*_{-} d a\right) \quad\right] l a d^{\circ} \partial_{-} d a$

Wera-GEN brother-3sG.POSs hit-3sG>SG.OBJ

'Wera ${ }_{i}$ 's brother ${ }_{j}$ hit him/her ${ }_{* i / * j / k} \cdot$ ' (Nikolaeva and Bárány 2019:244)

b. [овл Wera-h gәпо-m-ta ] sulor-p'iwa-s'

Wera-GEN boat-ACC-3sG.POSS fix-1sG>SG.OBJ-PST

'I fixed Wera's boat.'

(Nikolaeva 2014:145) 
Third, PIPs cannot occur if there is a free-standing third person pronoun, $n^{\prime} a^{\circ} n t a$ in (15a), in any of the core grammatical cases NOM, ACC or DAT in the same clause.

a. [ Pet'a-h $n^{\prime} e^{\circ} k a-m \quad / *^{*} \boldsymbol{n}^{\prime} \boldsymbol{e}^{\circ} \mathrm{ka}-\boldsymbol{m}-\mathrm{ta}$ ] $\boldsymbol{n}^{\prime} \boldsymbol{a}^{\circ}$ nta nedaraz- $d^{\circ} m$ Petya-GEN brother-ACC brother-ACC-3sG.POSS 3sG.DAT send-1sG 'I sent Peter $_{i}$ 's brother ${ }_{j}$ to him/her ${ }_{k}$ '

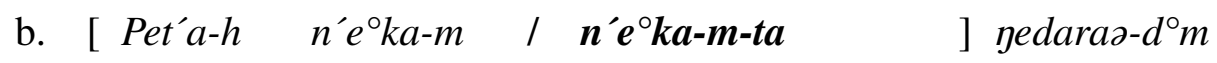
Petya-GEN brother-ACC brother-ACC-3sG.POss send-1SG

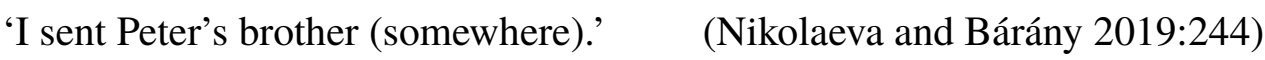

Regular low possessors are not subject to these distributional restrictions.

Since coreference between the PIP and the other third person DP blocking the PIP's presence is not necessary for these sentences to be ungrammatical, an account of these data in terms of binding theory seems unlikely at first glance. Rather, the fact that the restrictions all involve third person DPs suggests an analysis in terms of obviation (Dahlstrom 1986a,b, Aissen 1997, Jeanne and Hale 1987, Bruening 2001, Brittain 2001, Lochbihler 2012). Obviation governs the co-occurrence of third person DPs in a given syntactic domain, usually a finite clause, and crucially, only a single referent in the relevant domain can be proximate ("Proximate Uniqueness").

Following Bruening (2001), we will represent proximate status as a formal feature in syntax, which we call $[u$ Prox $]$. Bruening suggests for Passamaquoddy that the proximate feature of third person DPs needs to be checked by a functional head $\mathrm{H}$. We interpret this checking as the valuation of [ $u$ Prox $]$ by $\mathrm{H}$ via Reverse Agree (Zeijlstra 2012, Wurmbrand 2014).

Nikolaeva and Bárány (2019) argue that TN shows the effects of a syntactic obviation system (Aissen 1997). This means that not all DPs are overtly marked for their obviation status, but obviation nevertheless has syntactic consequences. To capture the 
distribution of PIPs with respect to other third person DPs in the clause, we suggest that there are two ways of receiving a proximate feature $[u$ Prox $]$ in $\mathrm{TN}$.

First, argument DPs can, but need not, be proximate. They are never overtly coded as proximate or obviative, but one of the arguments of the verb is assigned unvalued [uProx] in the verbal extended projection (in the sense of Grimshaw 2000). Which argument receives $[u \operatorname{Prox}] v$ is determined by pronominal status and syntactic position. If there are several third person arguments, the structurally highest one is $[u \operatorname{Prox}]$; for lexical DPs, either a subject or an agreeing (ACC) object is assigned $[u \operatorname{Prox}]$, in that order. Third person pronouns in TN always have animate referents, and so animacy is a grammaticalized feature for such pronouns. If present, a third person pronoun is assigned $[u$ Prox $]$, based on its inherent animacy even if there are higher third person lexical DPs — we take third person pronouns to be lexically specified as [ $u$ Prox $]$. These assumptions model that third person pronouns are highly ranked discourse participants and that this ranking is represented in syntax via syntactic features, as Bruening (2001:119) argues. This implementation also matches observations by Dryer (1992) and Aissen (1997) that animacy and grammatical function can determine proximate status.

Second, we propose that PIPs are always proximate and that they are merged already carrying a $[u$ Prox $]$ feature. That PIPs are inherently $[u$ Prox $]$ arguably reflects their prominent role in discourse: according to Nikolaeva and Bárány 2019, PIPs show properties of discourse topics, that is they behave like aboutness topics over longer stretches in discourse. By treating $[u$ Prox $]$ as inherent on PIPs, we model that $\mathrm{TN}$ has grammaticalized the proximate vs. obviative distinction on possessors (PIPs are proximate while regular lexical possessors are obviative). In this respect, $\mathrm{TN}$ differs from Passamaquoddy (Bruening 2001:128-130) and Plains Cree (Dahlstrom 1986a:116, Aissen 1997:711-714), for example, where all possessors are (inherently) proximate and possessed nouns are always obviative. In TN, when a PIP is present, the possessed noun must be obviative, like in other obviation systems. In contrast, since regu- 
lar possessors are obviative, they do not impose restrictions on the obviation status of their possessed noun: it can be either proximate or obviative, so there are situations in which the possessed noun outranks the possessor in obviation status.

The distributional restrictions on PIPs illustrated above follow from their being proximate: sentences with a PIP cannot contain another non-coreferential proximate DP, therefore PIPs cannot co-occur with third person subjects, objects controlling agreement, or third person personal pronouns. Thus, only PIPs, but not regular possessors, are able to compete with argument DPs for proximate status.

The three phenomena presented in this section illustrated the clause-level behavior of PIPs in TN. Based on the evidence from constituency, an analysis of PIPs in terms of external possession is unlikely. Instead, the distinct behavior of PIPs and low possessors with respect to binding and control indicates that PIPs are in a peripheral position in the DP from which they can c-command out of it.

\section{Proximate possessors as adjoined possessors}

C-command out of DP is possible if the possessor is not properly contained in but adjoined to it (May 1985, Chomsky 1986, Kayne 1994). Despić (2013) and Bošković and Şener (2014) argue for Serbo-Croatian and Turkish, respectively, that adjoined possessors of the subject induce violations of Conditions $\mathrm{B}$ and $\mathrm{C}$ if the object is bound by the possessor and that possessors of subjects can bind possessive pronouns in objects, indicating that they c-command out of the possessive phrase. While Despić (2013) and Bošković and Şener (2014) analyse these data in light of the universality of the DP hypothesis and argue that possessors are adjoined to NP rather than DP, we just focus on the possibility of adjunction in this paper.

We distinguish specifier positions from adjoined positions (like May 1985, but in contrast to Kayne 1994) so that it is only PIPs that can c-command out of DP. This leaves open the possibility that pronominal possessors are in SpecDP. (16) shows the 
structure we propose for PIPs in TN (adapted from Alexiadou et al. 2007:575). In TN, there are two DP-internal surface positions for lexical possessors. The PIP is adjoined to DP, meaning that not all of the DP's segments (bold-faced) dominate it—the PIP is thus not fully contained in it and can c-command out (cf. Despić 2013:244, Bošković and Şener 2014:111).

(16) Position of possessors in the Tundra Nenets DP

[DP PIP-GEN [DP D [AgrP PIP [ ${ }_{\text {Agr' }}$ Agr [PossP Low p'or-GEN [nP $n$ NP ]]]]]] $[u$ Prox $]$

LaTerza (2016:749-751) considers, but rejects, an analysis for possessor adjunction to DP for Bulgarian and Macedonian in part based on the fact that possessors follow determiners in these languages. The reverse order of possessors and determiners in TN makes LaTerza's (2016) argument irrelevant for this language and arguably supports an adjunction analysis. Further evidence for adjunction comes from Bošković and Şener's (2014) discussion of Turkish demonstratives and possessors. They argue that both possessors and demonstratives are adjoined to the NP in Turkish, since possessors can c-command out of the NP in either order. In TN, in contrast, PIPs must precede demonstratives, suggesting that only they, but not demonstratives, are adjoined.

Alexiadou et al. (2007:sec. 2.2, 572-575) suggest that adjoined positions for possessors make it difficult to derive similarities between subjects and possessors, in part because they are not case positions. However, low lexical possessors in TN are also case-marked, showing that the high adjoined position is not a case position, but a lower position is. In (16), this position is SpecPossP, which we assume to be the final position of low possessors and an intermediate position of PIPs, as both bear genitive case. This position precedes adjectives, quantifiers and other nominal modifiers (Nikolaeva 2014:171-173). From SpecPossP, PIPs move to SpecAgrP to agree with the possessed noun after being probed by Agr. Finally, PIPs are adjoined to the DP to 
be able to satisfy their [uProx] feature. We assume that this feature attracts PIPs to Agr in the first place. The PIP's $\varphi$-features value Agr, but its [ $u$ Prox $]$ feature is valued later (see below). A probe on Agr that is sensitive to discourse features (as in Miyagawa 2010, 2017) can also explain why overt pronominal possessors are higher than regular lexical possessors (in SpecDP or SpecAgrP) and why pronominal possessors usually control possessive agreement. It is also natural to assume that pronominal possessors have some discourse feature, as overt pronominal possessors are generally interpreted as contrastive, while null possessors generally have topical referents. Regular lexical possessors remain low as they are not seen by the probe on Agr. Functionally, this would reflect that proximate DPs are generally assumed to be more prominent and/or topical than obviative DPs and thus more likely to control agreement.

The positions in (16) are attested cross-linguistically (see Alexiadou et al. 2007:575 for examples), and the derivation proposed here resembles that of internal possessors in Hungarian passing through specifiers in the DP in some respects, but differs in others (Szabolcsi 1994, É. Kiss 2002:161-169, Georgi 2014:198-204, Dékány 2015). One difference between TN (and Serbo-Croatian/Turkish), on the one hand, and Hungarian, on the other hand, lies in how adjunction is motivated. In contrast to lexical possessors in TN, Hungarian internal possessors can be dative or nominative, and both types control agreement on the possessed noun. Nominative possessors are assumed to be in a position corresponding to SpecAgrP in (16) while dative possessors are higher, either adjoined or in SpecDP, depending on the analysis. Szabolcsi (1994) suggests that SpecDP serves as an "escape hatch" for the dative possessor, a position from where it can be extracted. É. Kiss (2002:169) argues that dative possessors project a $\mathrm{KP}$ and cannot be hosted in SpecDP but must be adjoined for licensing reasons. She cites the possible co-occurrence of dative, but not nominative possessors with demonstratives as evidence in favour of this analysis. As all lexical possessors in TN are in the genitive and can co-occur with demonstratives, this reasoning does not extend to TN. 
Moreover, the adjunction analysis in (16) provides a better account of the TN data because, unlike in Hungarian, high possessors in TN show DP-external behavior. Both nominative and dative possessors in Hungarian are ungrammatical when they corefer with an argument in the clause; É. Kiss (2002:33-40, 2008) explains this in terms of VP structure, not in terms of c-command out of the DP. Independently of the Hungarian facts, the adjoined position of PIPs in (16) accounts for their binding properties (see (8)) as well as for the fact that PIPs but not low possessors can control OC PRO (see (11), (12)).

The distributional restrictions of PIPs can be derived from the interaction of the feature $[u$ Prox $]$ with a functional head $\mathrm{H}$. This head, located below $\mathrm{CP}$, carries a [iProx] feature. DPs with unvalued [ $u$ Prox] enter a Reverse Agree relation with $\mathrm{H}$ in order to value $[u$ Prox $]$, resulting in $[u$ Prox: Prox $]$. Reverse Agree naturally derives multiple valuation by a single head, as in (17).

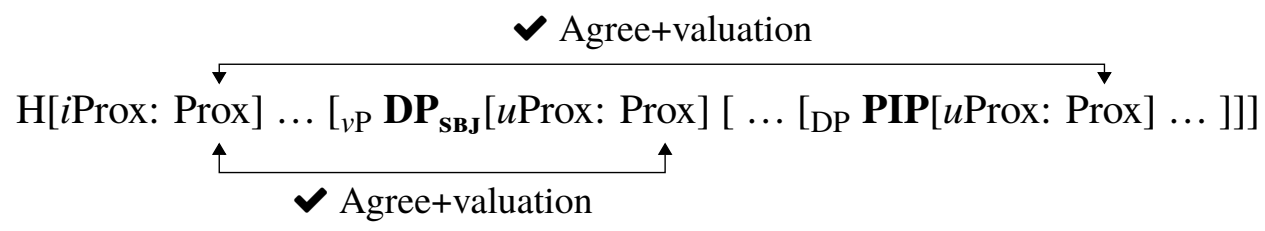

Examples (13)-(15) showed, however, that there cannot be two non-coreferential DPs with valued $[u$ Prox $]$ features in a single clause (Proximate Uniqueness). We propose that the adjoined position of PIPs in the possessive DP derives this restriction as well. Aissen's (1997: 710) principle of “co-linking" states that two DPs in an obviation domain can only both be proximate if they corefer. Thus, if co-linking holds and more than one DP with $[u$ Prox $]$ is valued, these two DPs must corefer. This can feed violations of binding theory if the syntactic relation between the two DPs is local enough. As we argued above, due to their position PIPs are local enough to enter binding relationships with other DPs in the clause. However, since PIPs are lexical DPs, any such binding relationships will lead to ungrammaticality: either the PIP will bind another lexical or pronominal DP that is construed to be coreferential, giving rise to a violation of Conditions B or C, respectively (as in (14a) and (15a)), or the PIP is 
bound by another DP, giving rise to a violation of Condition C (as in (13a) and examples involving stacking of PIPs).

To conclude, we have shown that lexical possessors that trigger agreement on the possessed noun in Tundra Nenets are internal to the possessive DP in terms of surface constituency, yet their syntactic properties show aspects of external behavior with respect to binding, control and obviation. We argued that this hybrid profile provides evidence that such possessors are adjoined to the possessive DP rather than being external or fully contained in it and we developed an analysis that derives all aspects of the special syntactic behavior of these possessors from their position at the edge of the DP, using independently motivated mechanisms like Agree and binding. Our analysis supports the view that possessors can be adjoined, as has been proposed for SerboCroatian, Turkish and Hungarian.

\section{References}

Aissen, Judith. 1997. On the syntax of obviation. Language 73:705-750.

Alexiadou, Artemis, Liliane Haegeman, and Melita Stavrou. 2007. Noun phrase in the generative perspective. Berlin: De Gruyter.

Bošković, Zeljko and Serkan Şener. 2014. The Turkish NP. In Crosslinguistic studies on noun phrase structure and reference, ed. by Patricia Cabredo Hofherr and Anne Zribi-Hertz, 102-140. Leiden: Brill.

Brittain, Julie. 2001. Obviation and coreference relations in Cree-Montagnais-Naskapi. Linguistica atlantica 23:69-91.

Broadwell, George Aaron. 2006. Choctaw reference grammar. Lincoln, NE: University of Nebraska Press.

Bruening, Benjamin. 2001. Syntax at the edge: Cross-clausal phenomena and the syntax of Passamaquoddy. Doctoral dissertation, MIT, Cambridge, MA.

Chomsky, Noam. 1986. Barriers. Cambridge, MA: MIT Press. 
Dahlstrom, Amy. 1986a. Plains Cree morphosyntax. Doctoral dissertation, University of California, Berkeley.

Dahlstrom, Amy. 1986b. Weak crossover and obviation. Annual Meeting of the Berkeley Linguistics Society 12:51-60.

Deal, Amy Rose. 2013. Possessor raising. Linguistic Inquiry 44:391-432.

Dékány, Éva. 2015. The syntax of anaphoric possessives in Hungarian. Natural Language \& Linguistic Theory 33:1121-1168.

Despić, Miloje. 2013. Binding and the structure of NP in Serbo-Croatian. Linguistic Inquiry 44:239-270.

Dryer, Matthew S. 1992. A comparison of the obviation systems of Kutenai and Algonquian. In Papers of the twenty-third Algonquian conference, ed. by William Cowan, 119-163. Ottawa: Carleton University.

É. Kiss, Katalin. 2002. The syntax of Hungarian. Cambridge: Cambridge University Press.

É. Kiss, Katalin. 2008. Free word order, (non)configurationality, and phases. Linguistic Inquiry 39:441-475.

Georgi, Doreen. 2014. Opaque interactions of Merge and Agree: On the nature and order of elementary operations. Doctoral dissertation, Universität Leipzig.

Grimshaw, Jane. 2000. Locality and extended projection. In Lexical specification and insertion, ed. by Peter Coopmans, Martin Everaert, and Jane Grimshaw, 115-133. Amsterdam: John Benjamins.

Jeanne, Laverne Masayesva and Ken Hale. 1987. Argument obviation and switchreference in Hopi. Anuario del Seminario de Filología Vasca 21:3-11.

Kayne, Richard S. 1994. The antisymmetry of syntax. Cambridge, MA: MIT Press. Landau, Idan. 1999. Possessor raising and the structure of VP. Lingua 107:1-37. Landau, Idan. 2013. Control in generative grammar: A research companion. Cambridge: Cambridge University Press. 
LaTerza, Ivana. 2016. Binding in English and South Slavic and the parameterized DP hypothesis. Linguistic Inquiry 47:741-753.

Lee-Schoenfeld, Vera. 2016. The syntax of external and internal possessor variation in German inalienable possession. STUF: Language Typology and Universals 69:113129.

Lochbihler, Bethany. 2012. Aspects of argument licensing. Doctoral dissertation, McGill University, Montréal.

Lødrup, Helge. 2009. External and internal possessors with body part nouns. SKY Journal of Linguistics 22:221-250.

May, Robert. 1985. Logical form: Its structure and derivation. Cambridge, MA: MIT Press.

Miyagawa, Shigeru. 2010. Why agree? Why move? Unifiying agreement-based and discourse-configurational languages. Cambridge, MA: MIT Press.

Miyagawa, Shigeru. 2017. Agreement beyond phi. Cambridge, MA: MIT Press.

Munro, Pamela. 2016. Chickasaw switch-reference revisited. In Switch reference 2.0, ed. by Rik van Gijn and Jeremy Hammond, 377-424. Amsterdam: John Benjamins.

Nikolaeva, Irina. 2014. A grammar of Tundra Nenets. Berlin: De Gruyter.

Nikolaeva, Irina and András Bárány. 2019. Proximate possessors. In Prominent internal possessors, ed. by András Bárány, Oliver Bond, and Irina Nikolaeva, 228258. Oxford: Oxford University Press.

Reinhart, Tanya. 1983. Coreference and bound anaphora: A restatement of the anaphora questions. Linguistics and Philosophy 6:47-88.

Sichel, Ivy. 2010. Towards a typology of control in DP. In Movement theory of control, ed. by Norbert Hornstein and Maria Polinsky, 245-266. Amsterdam: John Benjamins.

Szabolcsi, Anna. 1994. The noun phrase. In The syntactic structure of Hungarian, ed. by Ferenc Kiefer and Katalin É. Kiss. (Syntax and Semantics 27), 179-274. New York: Academic Press. 
Williams, Edwin. 1992. Adjunct control. In Control and grammar, ed. by Richard K.

Larson, Sabine Iatridou, Utpal Lahiri, and James Higginbotham, 297-322. Dordrecht: Kluwer Academic Publishers.

Wurmbrand, Susi. 2014. The Merge condition: A syntactic approach to selection. In Minimalism and beyond: Radicalizing the interfaces, ed. by Peter Kosta, Steven L. Franks, Teodora Radeva-Bork, and Lilia Schürcks, 130-166. Amsterdam: John Benjamins.

Zeijlstra, Hedde. 2012. There is only one way to agree. The Linguistic Review 29:491539.

Notes

We want to thank Éva Dékány, two anonymous reviewers and our editors for valuable comments. The research reported here was partly carried out as part of the AHRCfunded project "Prominent possessors" (AH/M010708/1). The AHRC's support is gratefully acknowledged.

${ }^{1}$ Abbreviations: 1 = first person, $2=$ second person, $3=$ third person, $\mathrm{ACC}=$ accusative, $\mathrm{CVB}=$ converb, $\mathrm{DAT}=$ dative, $\mathrm{DU}=$ dual, $\mathrm{FOC}=$ focus, $\mathrm{GEN}=$ genitive, $\mathrm{LOC}=$ locative, $\mathrm{NEG}=$ negative, $\mathrm{NOC}=$ non-obligatory control, $\mathrm{NOM}=$ nominative, $\mathrm{OBJ}=$ object, $\mathrm{OBL}=$ oblique, $\mathrm{OC}=$ obligatory control, $\mathrm{PIP}=$ prominent internal possessor, $\mathrm{PL}=$ plural, $\mathrm{POSs}=$ possessive $\mathrm{PST}=$ past, $\mathrm{REFL}=$ reflexive, $\mathrm{SBJ}=$ subject, $\mathrm{SG}=$ singular, $\mathrm{SR}=$ switch-reference, $\mathrm{SS}=$ same subject, $\mathrm{TN}=$ Tundra Nenets.

${ }^{2} \mathrm{TN}$ distinguishes imperfective and perfective verbs. The unmarked present tense of the latter refers to events in the immediate past, translated as such in (5) and other examples (Nikolaeva 2014:80).

${ }^{3}$ Accidental coreference between the low possessor and a possessive pronominal is presumably ruled out by competition with the alternative structure shown in (8) (cf. Reinhart 1983:75-78). 